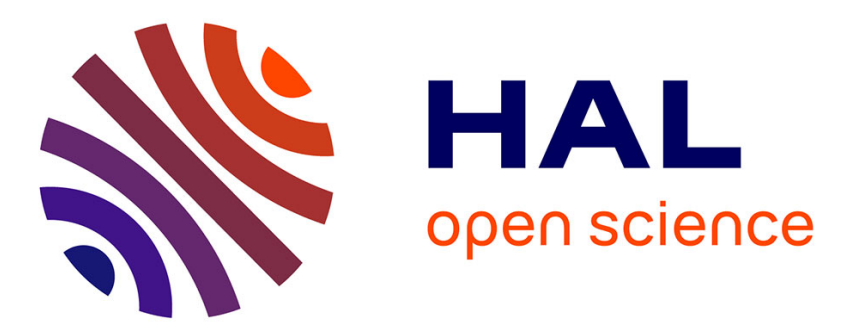

\title{
Evidence of Pd segregation and stabilization at edges of AuPd nano-clusters in the presence of CO: A combined DFT and DRIFTS study
}

Beien Zhu, Gode Thrimurthulu, Laurent Delannoy, Catherine Louis, Christine Mottet, Jerome Creuze, Bernard Legrand, Hazar Guesmi

\section{To cite this version:}

Beien Zhu, Gode Thrimurthulu, Laurent Delannoy, Catherine Louis, Christine Mottet, et al.. Evidence of Pd segregation and stabilization at edges of AuPd nano-clusters in the presence of CO: A combined DFT and DRIFTS study. Journal of Catalysis, 2013, 308, pp.272-281. 10.1016/j.jcat.2013.08.022 . hal-03184658

\section{HAL Id: hal-03184658 \\ https://hal.science/hal-03184658}

Submitted on 29 Mar 2021

HAL is a multi-disciplinary open access archive for the deposit and dissemination of scientific research documents, whether they are published or not. The documents may come from teaching and research institutions in France or abroad, or from public or private research centers.
L'archive ouverte pluridisciplinaire HAL, est destinée au dépôt et à la diffusion de documents scientifiques de niveau recherche, publiés ou non, émanant des établissements d'enseignement et de recherche français ou étrangers, des laboratoires publics ou privés. 


\section{Evidence of Pd segregation and stabilization at edges of AuPd nano-clusters in the presence of CO: a combined DFT and DRIFTS study}

Beien Zhu ${ }^{1,2}$, Gode Thrimurthulu ${ }^{1}$, Laurent Delannoy ${ }^{1}$, Catherine Louis ${ }^{1 *}$, Christine Mottet ${ }^{3}$, Jerome Creuze ${ }^{4}$, Bernard Legrand ${ }^{5}$ and Hazar Guesmi ${ }^{1,2^{*}}$

1 CNRS-UPMC Université Paris 6, UMR 7197, Laboratoire de Réactivité de Surface, F-75005, Paris, France

2 CNRS-ICG UMR 5253, équipe MACS, 8 rue de l'Ecole Normale 34296, Montpellier, France

3 CNRS-CINAM UMR 7325, Campus de Luminy 13288 Marseille, France

4 ICMMO, LEMHE Bâtiment 410, Université Paris-Sud, 91405 Orsay, France

5 CEA, Service de Recherches de Métallurgie Physique, Saclay, France

* catherine.louis@upmc.fr

* hazar.guesmi@upmc.fr

\section{Abstract}

Combined Density Functional Theory (DFT) calculations and Diffuse Reflectance Infrared Fourier Transform Spectroscopy (DRIFTS) were performed to study the distribution of Pd atoms in bimetallic AuPd nanoparticles in the presence of adsorbed CO. Compared to vacuum condition, the results showed evidence of Pd surface enrichment where both Pd monomers and Pd dimers could exist. The energetic stability calculated for several alloy configurations evidenced the preference of Pd to occupy under-coordinated edge sites in the presence of CO gas. Moreover, the calculation of the vibrational frequencies of adsorbed $\mathrm{CO}$ for the first time allowed the fine assignment of the complex experimental DRIFTS bands of CO interacting with the bimetallic nanoparticles and their evolution with time exposure. Electronic structure analysis shows preponderant $\pi$-back-donation from under-coordinated $\mathrm{Pd}$ to $\mathrm{CO}$ inducing strong bonding on edge sites.

\section{Keywords:}

CO adsorption, AuPd, DFT, Catalysis, DRIFTS, Nanoalloy 


\section{Introduction}

In surface science and catalysis, the $\mathrm{CO}$ molecule is commonly used as an indirect probe to identify the nature of metal surface sites [1-2]. Its application is based on the statement that IR bands of carbonyl adsorbed species recorded after $\mathrm{CO}$ introduction are relevant to specific $\mathrm{CO} /$ metal interactions and serve as a fingerprint of the adsorption site. The use of $\mathrm{CO}$ to characterize the local structure of nanoalloy catalysts is particularly important to understand their appealing chemical properties.

Recently, surfaces and particles of AuPd alloys were investigated regarding the role of ensembles in many chemical reactions such as hydrogen peroxide synthesis [3], acetoxylation of ethylene to vinyl acetate (VA) [4-5] and CO oxidation [6]. It appeared from these studies that the knowledge of the structure and surface composition of AuPd nanoalloy particles is crucial to interpret their catalytic performance. In addition, the bonding of adsorbates under reaction conditions may, in some cases, induce modifications of local atomic composition and surface structure, changing the activity and the selectivity of the catalyst. In particular for the AuPd system, the surface segregation of Pd was reported to occur in the presence of reactive gas such as $\mathrm{CO}[7,8]$, $\mathrm{NO}$ [9], $\mathrm{O}, \mathrm{O}_{2}[10,11]$ and $\mathrm{CO}+\mathrm{O}_{2}$ [12]. Furthermore, recent theoretical work of Ismail et al. [13] has indicated preferential segregation of Pd towards the interface between the AuPd nanoparticles and the MgO oxide support. Thus, for low Pd loading, one can imagine that a competition may occur between burying the active Pd atoms at the metal-oxide interface rather than allowing them to migrate to the surface. This emphasises the subtlety of the segregation process under real conditions and the necessity to combine different investigation methods to describe the behaviour of the alloy under reaction conditions.

Goodman and co-workers studied the effect of $\mathrm{CO}$ pressure on the low temperature oxidation reaction using two types of Au-Pd model catalysts; thin alloy films on $\mathrm{Mo}(110)$ and 
AuPd nanoparticles on a $\mathrm{TiO}_{2}$ thin film on $\mathrm{Mo}(110)[6,14]$. At low $\mathrm{CO}$ pressure $\left(1 \times 10^{-7}\right.$ Torr), the catalysts were inactive in $\mathrm{CO}$ oxidation. The authors deduced that alloying with $\mathrm{Au}$ forms isolated surface $\mathrm{Pd}$ sites that were unable to dissociate $\mathrm{O}_{2}$. At elevated $\mathrm{CO}$ pressure (816 Torr), the Au-Pd alloys showed superior reactivity compared to pure Pd catalysts. The authors concluded that $\mathrm{Pd}$ surface segregation under high $\mathrm{CO}$ pressure exposure led to the formation of contiguous $\mathrm{Pd}$ sites, at least $\mathrm{Pd}$ dimers, able to dissociate $\mathrm{O}_{2}$. These experiments coupled with IR (IRAS) studies showed that neither $\mathrm{Au}$, nor isolated Pd atoms were able to dissociate $\mathrm{O}_{2}$. Only contiguous Pd sites, evidenced by the formation of bridging $\mathrm{CO}$ species, could dissociate $\mathrm{O}_{2}$ and lead to active catalysts. Moreover, Goodman showed that Pd started to segregate to the surface of $\mathrm{AuPd}(100)$ from $260 \mathrm{~K}$ and $\mathrm{CO}$ pressures as low as $10^{-3}$ Torr. Therefore, the determination of the structure and chemical order of the surface nanoparticles under vacuum and the control of their changes under operating conditions are determining for optimizing the catalyst performance.

The theoretical methods for studying properties of bimetallic particles have recently evolved into an important tool [15], which allows one to predict not only equilibrium structures at $0 \mathrm{~K}$ but also phase transitions [16-17] and growth nanostructures [18-19]. For the AuPd system, several theoretical papers have dealt with the study of the surface structure of the alloy in order to explain their catalytic reactivity [20-23]. A Density functional study of low Pd concentrations on Au clusters has shown that Pd atoms tend to occupy the (111) facets leaving the $\mathrm{Au}(001)$ facets free [23]. Neyman et al. [24] investigated the role of the edges, which represent interesting morphological elements of nanoparticles with respect to catalytic activity. These authors have reported that the stabilization of gold at the edges of PdAu nanoparticles (with high Pd content) is due to their higher flexibility for surface relaxation, which minimizes the strain induced by the larger atomic radius of $\mathrm{Au}$ as compared to $\mathrm{Pd}$. 
One feature of the vast majority of these studies is that they do not take into account the possibility that the surface composition can be modified during gas exposure. This is a serious drawback that may prevent reliable description of the nanoparticles reactivity that mainly depends on the structure configuration of the surface. Although in the presence of $\mathrm{CO}$, the segregation of $\mathrm{Pd}$ to the surface was predicted by experimental $[8,25]$ and theoretical studies $[7,9-11,14,26]$, very little is known about the distribution of Pd on the surface and their coordination as well as the facets on which the Pd atoms are stabilized. With the intention to fill this knowledge gap, we combined DFT and DRIFTS methods to investigate the segregation of Pd and to identify the precise chemical ordering of the surface of AuPd nanoparticles as well as its change during $\mathrm{CO}$ exposure. As far as we know, we report herein the first fine assignment of the complex experimental DRIFTS bands of CO interacting with the Au-Pd bimetallic nanoparticles.

In this paper, the results are organized as follows: the first part reports the experimental DRIFT spectra of AuPd nanoparticles supported on alumina during CO gas exposure. In the second part, the experimental data are assessed from the computational point of view. Firstly, the main insights of Pd segregation are discussed, based on the calculation of the segregation energies of Pd (isolated and dimers) on low index Au (100) and (111) surfaces in the presence and absence of adsorbed CO molecule. Secondly, 38-atom clusters are used to monitor the $\mathrm{CO}$ interactions as a function of surrounding chemical environment and to extract information of the structural arrangement under reacting gas. More precisely, $\mathrm{CO}$ interactions in a series of $\mathrm{Au}_{38-\mathrm{n}} \mathrm{Pd}_{\mathrm{n}}(\mathrm{n}=1,2)$ clusters with different possible $\mathrm{Pd}$ locations and coordinations are theoretically investigated by means of DFT minimum energy optimizations and second derivative force constant calculations. The calculated theoretical harmonic frequencies are then overviewed and compared to the IR experimental attributions, allowing a fine assignment of the IR bands. Finally, the Pd distribution in the presence of $\mathrm{CO}$ on the particle 
surface is described based on electronic and energetic analysis and discussed in detail to amend the interpretation of the experimental observations.

\section{Experimental and Theoretical methods}

\section{1. Experimental details}

A AuPd/ $/ \mathrm{Al}_{2} \mathrm{O}_{3}$ sample with a $\mathrm{Au} / \mathrm{Pd}$ atomic ratio of $20\left(\mathrm{AuPd}-20 / \mathrm{Al}_{2} \mathrm{O}_{3}\right)$ was prepared using the deposition-precipitation with urea (DPU) method. $3 \mathrm{~g}$ of alumina in $290 \mathrm{~mL}$ of distilled water was introduced into a glass reactor with double walls, allowing water circulation at $80{ }^{\circ} \mathrm{C}$ between the walls and therefore, a homogeneous and well-controlled temperature of $80{ }^{\circ} \mathrm{C}$ of the suspension. Then $6.0 \mathrm{~mL}$ of a solution of $\mathrm{HAuCl}_{4} \cdot 3 \mathrm{H}_{2} \mathrm{O}\left(2.510^{-2}\right.$ M) and $1.6 \mathrm{~mL}$ of a solution of $\mathrm{Pd}\left(\mathrm{NH}_{3}\right)_{4}\left(\mathrm{NO}_{3}\right)_{2}\left(4.710^{-3} \mathrm{M}\right)$, corresponding to an atomic $\mathrm{Au} / \mathrm{Pd}$ ratio of 20 , were added under vigorous stirring, followed by the addition of $0.9 \mathrm{~g}$ of solid urea. The suspension was stirred at $80{ }^{\circ} \mathrm{C}$ for $16 \mathrm{~h}$ in the absence of light. The solid was then separated by centrifugation and washed with $300 \mathrm{~mL}$ of water. This procedure of centrifugation-washing was repeated four times, and after the fourth washing, the addition of a few drops of silver nitrate to the supernatant did not reveal any traces of chlorides. Finally, the samples were dried under vacuum at RT in a desiccator in the dark for about $12 \mathrm{~h}$.

Reference samples of monometallic $\mathrm{Au} / \mathrm{Al}_{2} \mathrm{O}_{3}$ with 1 wt $\% \mathrm{Au}, \mathrm{Pd} / \mathrm{Al}_{2} \mathrm{O}_{3}$ with $\mathrm{Pd}$ loading of $\sim 270 \mathrm{ppm}$, which corresponds to the Pd loading in alloy samples with a $\mathrm{Au} / \mathrm{Pd}$ ratio of 20 , were also prepared by deposition-precipitation method. The $\mathrm{Au} / \mathrm{Al}_{2} \mathrm{O}_{3}$ sample was prepared according to the same procedures as above, except for the absence of $\mathrm{Pd}\left(\mathrm{NH}_{3}\right)_{4}\left(\mathrm{NO}_{3}\right)_{2}$. The reference $\mathrm{Pd} / \mathrm{Al}_{2} \mathrm{O}_{3}$ sample was prepared by deposition-precipitation with $\mathrm{Na}_{2} \mathrm{CO}_{3}$ and not with urea. 3 grams of alumina was dispersed in $150 \mathrm{~mL}$ of distilled water, at $\mathrm{RT}$, then $1.35 \mathrm{~mL}$ of $\mathrm{PdCl}_{2}$ solution $\left(1.0 \mathrm{~g} \cdot \mathrm{L}^{-1}\right)$ was added under stirring, and the $\mathrm{pH}$ 
was adjusted to 10.5 by dropwise addition of a solution of $\mathrm{Na}_{2} \mathrm{CO}_{3}(1 \mathrm{M})$. After $1 \mathrm{~h}$ of stirring, the solid was gathered by centrifugation and then washed four times in distilled water. Finally, the samples were dried under vacuum at RT and stored in a desiccator in the dark (as prepared samples).

Diffuse Reflectance Infrared Fourier Transform Spectroscopy (DRIFTS) was performed with an IFS 66V Bruker spectrometer. The sample compartment of the cell (collector from Spectratech) was filled with the as prepared sample. The sample ( 20 mg) was first reduced in situ in $50 \mathrm{~cm}^{3} \cdot \mathrm{min}^{-1}$ of $5 \% \mathrm{v} / \mathrm{v} \mathrm{H}_{2} / \mathrm{Ar}$ to $300{ }^{\circ} \mathrm{C}\left(\mathrm{Au} / \mathrm{Al}_{2} \mathrm{O}_{3}\right)$ or $500{ }^{\circ} \mathrm{C}$ $\left(\mathrm{Pd} / \mathrm{Al}_{2} \mathrm{O}_{3}\right.$ and $\left.\mathrm{AuPd}-20 / \mathrm{Al}_{2} \mathrm{O}_{3}\right)$ at $2{ }^{\circ} \mathrm{C} \mathrm{min}^{-1}$. The sample was maintained at the final temperature during $2 \mathrm{~h}$. Then the cell was cooled to RT and purged with He. A spectrum was recorded under $\mathrm{He}$ and used as reference. Then a flow $\left(50 \mathrm{~cm}^{3} \mathrm{~min}^{-1}\right)$ of $1 \% \mathrm{v} / \mathrm{v} \mathrm{CO}$ in He was introduced at RT, and spectra were recorded. The intensity of the spectrum under $\mathrm{CO} / \mathrm{He}$ was expressed as $\log \left(\frac{1}{R^{\prime}}\right)$. The relative reflectance $R^{\prime}$ is given by $R^{\prime}=\frac{R}{R_{\infty}}=\frac{I_{c o / H e}}{I_{H e}}$.

\section{2. Theoretical details}

To study the $\mathrm{CO}$ adsorption on AuPd surfaces and nano-clusters, periodic selfconsistent DFT calculations were performed using the Vienna ab-initio simulation package (VASP) [27]. The exchange-correlation energy was calculated within the Perdew, Burke and Ernzerhof formulation of the generalized-gradient approximation (GGA-PBE) [28]. The valence electrons were treated explicitly, and their interactions with the ionic cores were described by the projector augmented-wave method (PAW) [29,30], which allowed the use of a low energy cut off equal to $415 \mathrm{eV}$ for the plane-wave basis. The positions of the atoms in the super cell were relaxed until the total energy differences fell below $10^{-4} \mathrm{eV}$. Vibrational spectra were calculated for selected surface species within the harmonic approximation. Only the CO center and its first and second neighbors (gold and palladium atoms) were considered 
in the Hessian matrix. This matrix was computed by the finite difference method followed by a diagonalization procedure. The eigenvalues of the resulting matrix led to the frequency values.

For the calculation of segregation energy of $\mathrm{Pd}$ in the presence and absence of $\mathrm{CO}, \mathrm{Pd}$ impurities (one or two atoms) were substituted in different layers of the $\mathrm{Au}(111)$ and $\mathrm{Au}(100)$ surfaces as in references $[10,11]$. The slabs consist of $3 \times 3$ unit cells separated by $15 \AA$ of vacuum space. Atomic relaxation of all metallic atoms in the top four layers of the slab and the $\mathrm{CO}$ molecule was allowed. The bottom two layers were constrained at the bulk geometry with a calculated equilibrium lattice constant of $4.18 \AA$ comparable to the experimental value of $4.08 \AA$ [31]. The Brillouin zone integrations for flat surfaces were performed on a Monkhorst-Pack $(3 \times 3 \times 1)$ k-point mesh. The segregation energy $\left(E_{\text {seg }}\right)$ of $\mathrm{Pd}$ in the gold matrix was defined by equation 1 .

$$
E_{\text {seg. }}=\left[E_{A u P d(P d x-l a y e r)}-E_{A u P d(P d 4 t h-l a y e r)}\right] / N_{P d}
$$

where $E_{\mathrm{AuPd}(\mathrm{Pd} x \text {-layer })}$ represents the total energy of the AuPd alloy system with $\mathrm{N}_{\mathrm{Pd}}$ the number

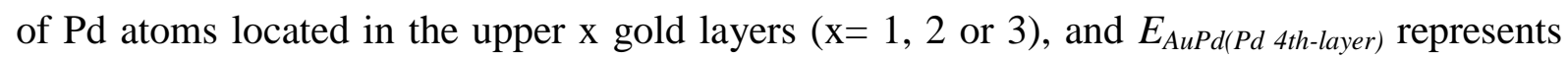
the total energy of the AuPd alloy system with the Pd atoms located in the $4^{\text {th }}$ gold layer, which corresponds to the presence of Pd atoms in the "bulk" gold. In the presence of adsorbed $\mathrm{CO}$ molecule, the segregation energies were calculated by considering the energetically most stable configuration regarding the position of Pd in gold slabs.

To model nanoparticles, a cubic cell with sides of $2 \mathrm{~nm}$ was chosen to provide enough spacing between metal clusters in the neighboring repeated cells. A cluster model of 38 atoms with cubo-octahedral shape was cut from bulk $f c c$ metal and presents (111) and (100) facets. The 38 -atom cluster was selected because size 38 is a "magic" number for the truncated octahedral structure, which possesses a high symmetry, thus simplifying the analysis of ligand adsorption [26]. Moreover, as hexagonal local arrangements are a common 
occurrence on the surface of nanoparticles [32], 38-atom cluster is often taken as a model of crystalline-like structure and thus also as representative of larger clusters [26, 33-35]. During geometry optimization all atoms were allowed to relax. The Gamma point was used in the Brillouin-zone integration. According to their coordination numbers, the surface atoms of the considered cluster could be divided into two groups, the edge sites with coordination number of 6 and the facet sites with coordination of 9 . Hereafter, we define all possible $\mathrm{CO}$ adsorption sites as follows: two top sites, edge site (TOP-ed) and facet site (TOP-fc); two bridge sites, between two edge atoms (BDG-ed-ed) and between edge and facet atoms (BDG-ed-fc); threefold sites between three adjacent atoms on (111) facet and four-fold sites between four adjacent atoms on (100). The adsorption energy of the CO molecule was calculated from equation 2:

$$
E_{a d s}=E_{c l u+C O}-E_{C O}-E_{c l u s t e r}
$$

where $E_{c l u+C O}$ is the total energy of the $\mathrm{CO}$ adsorbed on cluster system, $E_{C O}$ and $E_{\text {cluster }}$ are the total energies of free $\mathrm{CO}$ and metal cluster, respectively.

\section{Results and discussions}

\section{III.1. Experimental Results}

In our earlier studies, we reported that the method of preparation of supported gold catalysts by deposition-precipitation (DP) is efficient for obtaining small particles with narrow size distribution over $\mathrm{TiO}_{2}$ and other supports $[8,36]$. In the present investigation, we employed also this method to prepare $\mathrm{Au}, \mathrm{Pd} / \mathrm{Al}_{2} \mathrm{O}_{3}$ and $\mathrm{AuPd}-20 / \mathrm{Al}_{2} \mathrm{O}_{3}$ samples. The TEM characterization of such catalysts has been previously reported and indicated the presence of metallic nanoparticles in the range $2-3 \mathrm{~nm}[8,25]$.

To study the CO adsorption on these samples, we used the DRIFT spectroscopy which can provide information about the nature and population of different adsorption sites (linear, 
bridged ...) present on the surface of metallic or bimetallic particles, and thus may give some information on the elemental composition of the surface.

As references, Figure 1 shows the DRIFT spectra in the carbonyl region $\left(1800-2400 \mathrm{~cm}^{-1}\right)$ of the monometallic $\mathrm{Au} / \mathrm{Al}_{2} \mathrm{O}_{3}$ and $\mathrm{Pd} / \mathrm{Al}_{2} \mathrm{O}_{3}$ samples, recorded after 10 min under a $\mathrm{CO} / \mathrm{He}$ flow. It is worth noting that after $10 \mathrm{~min}$ under $\mathrm{CO} / \mathrm{He}$, the spectra did not evolved anymore. $\mathrm{Au} / \mathrm{Al}_{2} \mathrm{O}_{3}$ exhibited a single intense band at $2104 \mathrm{~cm}^{-1}$, which has been previously attributed to $\mathrm{CO}$ linearly adsorbed on low coordination sites of metallic Au [37-39]. No CO bridged species could be detected on the $\mathrm{Au} / \mathrm{Al}_{2} \mathrm{O}_{3}$ sample, which is in accordance with most of the studies reported in the literature. $\mathrm{Pd} / \mathrm{Al}_{2} \mathrm{O}_{3}$ exhibited two broad bands, one in the region 2150$2000 \mathrm{~cm}^{-1}$, centered at $2077 \mathrm{~cm}^{-1}$ and the other in the region $2000-1800 \mathrm{~cm}^{-1}$, centered at 1910 $\mathrm{cm}^{-1}$. These bands are assigned to CO linearly adsorbed on metallic Pd $\left(2077 \mathrm{~cm}^{-1}\right)$ and to multi-bonded CO adsorbed on metallic Pd planes $\left(1910 \mathrm{~cm}^{-1}\right)$ with combination of bridged (2000-1895 $\left.\mathrm{cm}^{-1}\right)$ and three-fold bridged CO species (1920-1830 $\left.\mathrm{cm}^{-1}\right)$ [40-42].

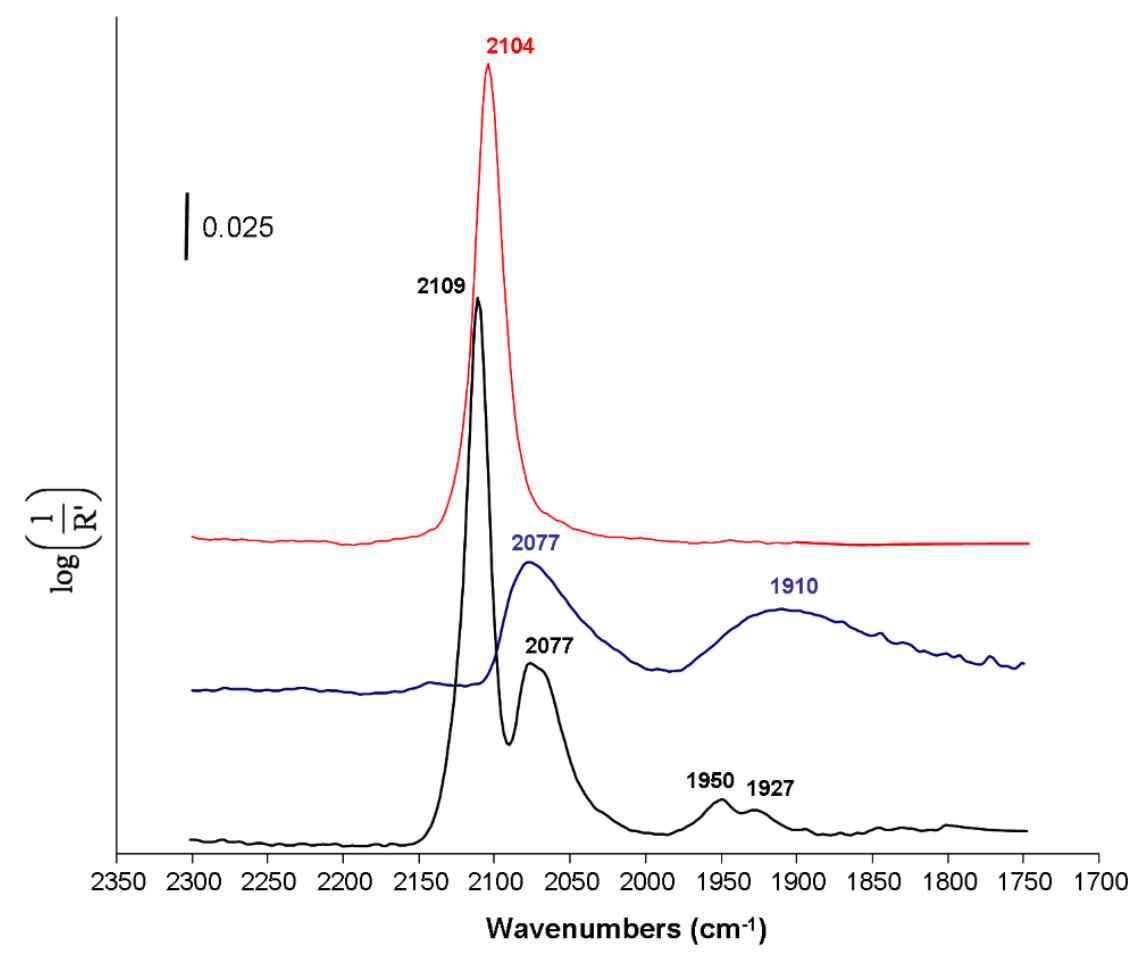

Figure 1: DRIFT spectra in the carbonyl region of $\mathrm{Au} / \mathrm{Al}_{2} \mathrm{O}_{3}$ (red line) and $\mathrm{Pd} / \mathrm{Al}_{2} \mathrm{O}_{3}$ (blue line) and $\mathrm{Au}-\mathrm{Pd}(20) / \mathrm{Al}_{2} \mathrm{O}_{3}$ (black line) after 2 min under $\mathrm{CO} / \mathrm{He}$. 

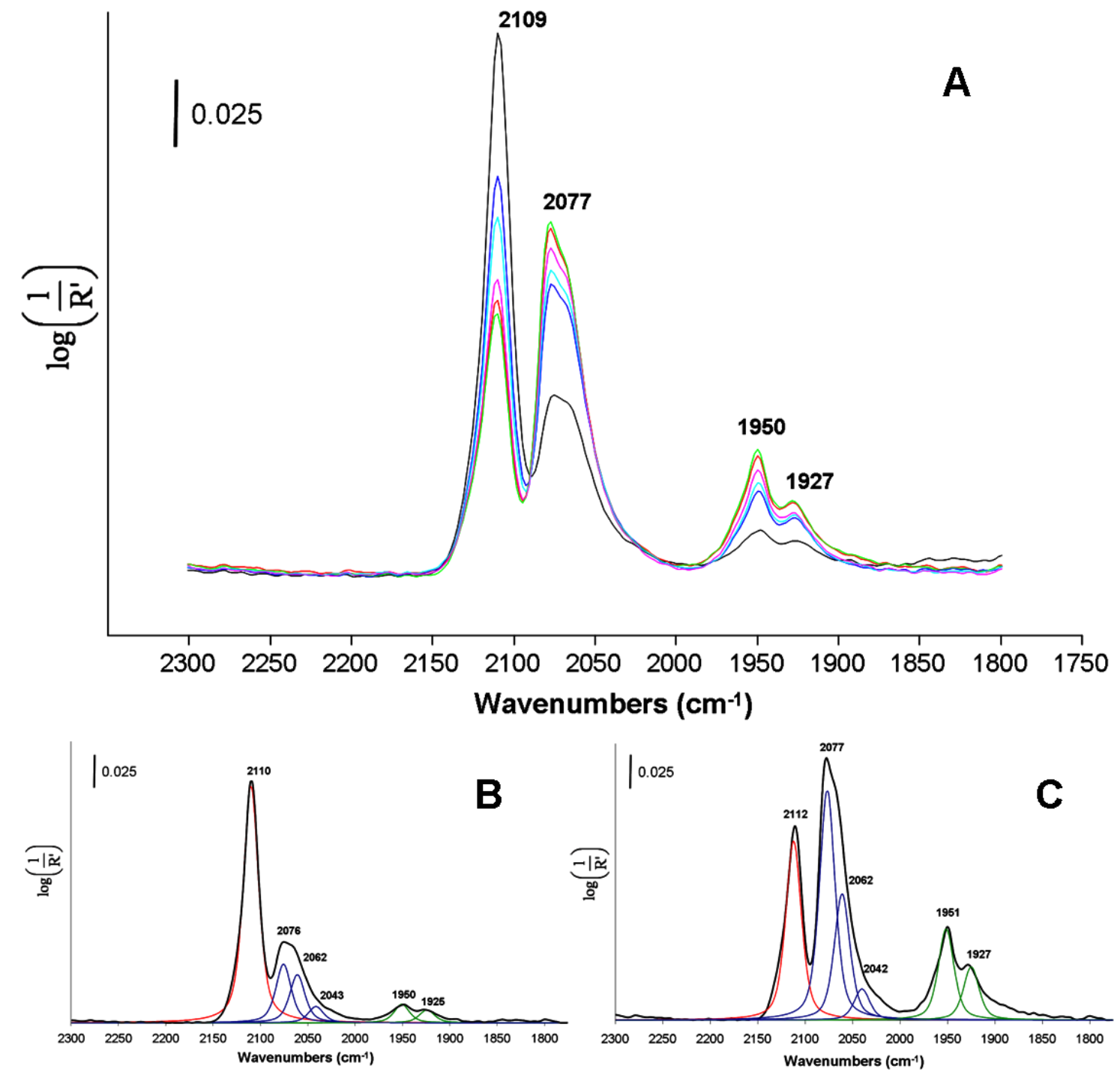

Figure 2: DRIFT spectra in the carbonyl region of $\mathrm{Au}-\mathrm{Pd}(20) / \mathrm{Al}_{2} \mathrm{O}_{3}$ with time under $\mathrm{CO} / \mathrm{He}$ (first spectra after 2 min under $\mathrm{CO} / \mathrm{He}$ (black line), last spectra after 90 min (green line) (A); Decomposition of the first $\mathrm{Au}-\mathrm{Pd}(20) / \mathrm{Al}_{2} \mathrm{O}_{3}$ spectrum under $\mathrm{CO} / \mathrm{He}(\mathrm{B})$; Decomposition of the last $\mathrm{Au}-\mathrm{Pd}(20) / \mathrm{Al}_{2} \mathrm{O}_{3}$ spectrum under $\mathrm{CO} / \mathrm{He}(\mathrm{C})$.

Figure 1 also shows the first DRIFT spectrum of a AuPd-20/Al ${ }_{2} \mathrm{O}_{3}$ bimetallic sample recorded after 2 min under $\mathrm{CO} / \mathrm{He}$. This sample exhibits several bands in the carbonyl region: a sharp band located at $2110 \mathrm{~cm}^{-1}$ that can be assigned as previously to CO linearly adsorbed on low coordinated metallic Au sites, a band at $2077 \mathrm{~cm}^{-1}$, clearly containing several components, analogous to the one observed for CO linearly adsorbed on metallic Pd sites (Figure 1) and 
two weak bands at $1950 \mathrm{~cm}^{-1}$ and $1927 \mathrm{~cm}^{-1}$ which may correspond to bridged CO species. It is noteworthy that the low intensity of these latter bands and the absence of bands below 1900 $\mathrm{cm}^{-1}$, formerly assigned to $\mathrm{CO}$ on three-fold bridged Pd sites, indicate that the dilution of Pd in $\mathrm{Au}$ on the particle surface limits the formation of multi-bonded $\mathrm{CO}$. Such observations were already made in previous studies on AuPd films and supported AuPd nanoparticles [4345]. Although we cannot discard the possible presence of monometallic gold particles in the $\mathrm{Au}-\mathrm{Pd} / \mathrm{Al}_{2} \mathrm{O}_{3}$ catalyst, the observations described above as well as previous characterization by TPR [46] and catalytic results obtained in selective hydrogenation of p-chloronitrobenzene [46] and butadiene [8], support the assumption that most of the Pd is contained in bimetallic AuPd particles.

Contrary to the monometallic samples, the spectra of the $\mathrm{Au}-\mathrm{Pd} / \mathrm{Al}_{2} \mathrm{O}_{3}$ catalyst do not stabilise rapidly under $\mathrm{CO}$ and large changes in the band intensity are observed with time under $\mathrm{CO} / \mathrm{He}$ (Figure 2A). Indeed, the band corresponding to linear $\mathrm{CO}$ on $\mathrm{Au}$ decreases with time while the ones assigned to linear and bridge $\mathrm{CO}$ on Pd increase. Such an observation can be related to modifications in the surface composition of the bimetallic nanoparticles, with a progressive enrichment of the surface in Pd. Palladium surface segregation in AuPd alloys under $\mathrm{CO}$ or $\mathrm{CO} / \mathrm{O}_{2}$ was previously reported $[6-8,12-14,47-48]$ and the segregation of the second metal was also observed for other gold-containing bimetallic systems such as Au-Pt, $\mathrm{Au}-\mathrm{Ni}$ or Au-Rh [49-51]. We tentatively decomposed the broad band corresponding to linear $\mathrm{CO}$ on $\mathrm{Pd}$ of the $\mathrm{Au}-\mathrm{Pd} / \mathrm{Al}_{2} \mathrm{O}_{3}$ spectra and the results of the decomposition are presented in Figure $2 \mathrm{~B}$ and $2 \mathrm{C}$ for the first and the last spectrum recorded under $\mathrm{CO} / \mathrm{He}$, respectively. Three components at 2076, 2062 and $2043 \mathrm{~cm}^{-1}$ were obtained. Their intensities, as well as those of the bands at 1950 and $1927 \mathrm{~cm}^{-1}$, increase with time under $\mathrm{CO} / \mathrm{He}$ as shown in Figures $2 \mathrm{~B}$ and $2 \mathrm{C}$. Among the three components of the band of linearly adsorbed $\mathrm{CO}$ on $\mathrm{Pd}$, the one at $2076 \mathrm{~cm}^{-1}$ undergoes the largest increase. 
These experimental data provide evidence of Pd surface enrichment of the AuPd nanoparticles under exposure to $\mathrm{CO}$ at room temperature. The assignment of the various components of the $\mathrm{CO}$ on Pd bands is not straightforward but could afford valuable insight into the possible specific surface sites occupied by the migrating Pd atoms in the initial stage and during the segregation process. In the following section, we present the theoretical assignments of such components.

\section{III.2. DFT calculation results}

\section{Pd segregation on semi-infinite surfaces}

In order to gain insight into the segregation behavior of $\mathrm{Pd}$ in the presence of carbon monoxide, we performed DFT calculations of the segregation energies of $\mathrm{Pd}$ atoms on $\mathrm{Au}$ (100) and (111) surfaces (calculated from Eq. (1)). Indeed, the (111) and (100) orientations could form the main facets of stable nanoparticles. Figures $3 \mathrm{~A}$ and $\mathrm{B}$ report the evolutions of the segregation energies of one $\mathrm{Pd}$ atom (Pd monomer) and of a pair of adjacent $\mathrm{Pd}$ atoms ( $\mathrm{Pd}$ dimer) as a function of their position in the (100) and (111) gold matrix, respectively. These evolutions of the segregation energies $\left(E_{\text {seg }}\right)$ are analyzed in the presence and absence (vacuum conditions) of $\mathrm{CO}$ gas.
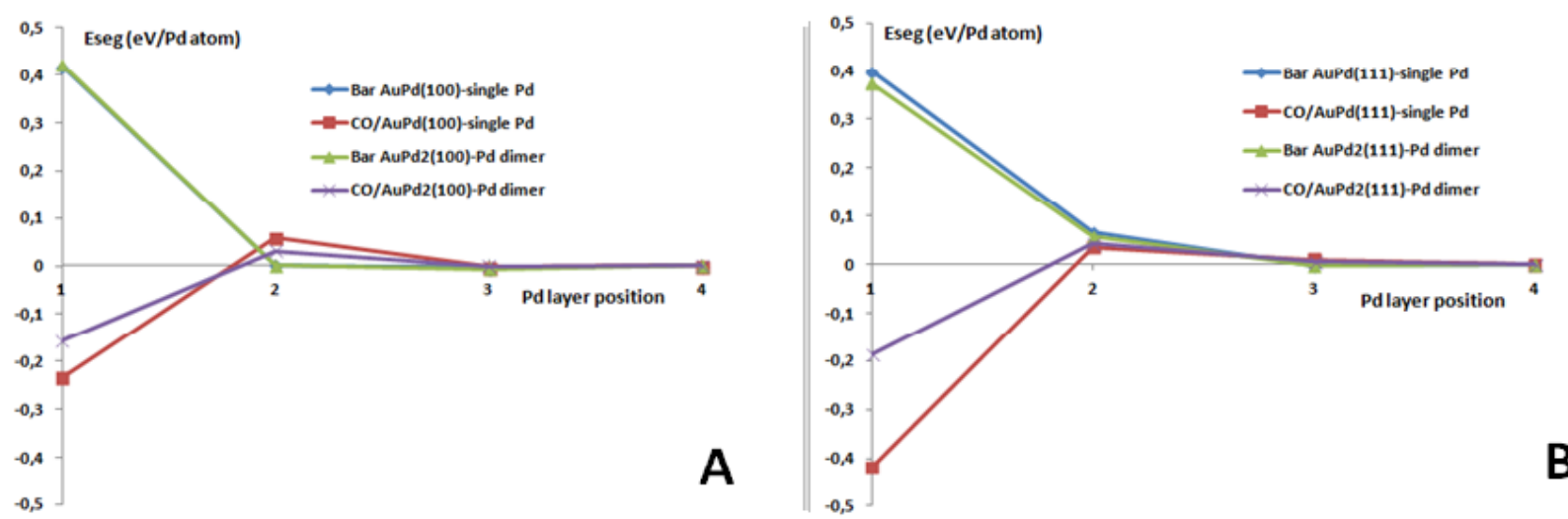
Figure 3: Evolution of the segregation energies $\left(E_{\text {seg }}\right)(\mathrm{eV} / \mathrm{Pd}$ atom) of monomer and dimer Pd atoms from the gold "bulk" (4 $4^{\text {th }}$ layer in the sub-surface) to the (100) (A) and the (111) (B) surface. DFT calculations were performed in the presence and absence of one adsorbed CO molecule (on top of Pd monomer and bridging dimer Pd).

Under vacuum conditions, the Pd monomer and dimer present a similar behavior on both facets; they are highly unstable in the surface and in the sub-surface layers (for Pd monomer, $E_{\text {seg }}=+0.42 \mathrm{eV} /$ atom and $+0.39 \mathrm{eV} /$ atom for $(100)$ and (111) surface, respectively). The preference of Pd to be in the bulk gold (i.e., third and fourth layers) is due to the lower surface energy of gold compared to that of the Pd (experimental values are $0.64 \mathrm{eV} /$ atom for $\mathrm{Au}[52], 0.86 \mathrm{eV} / \mathrm{atom}$ for Pd [53]).

In the presence of adsorbed $\mathrm{CO}$, the segregation energies change drastically and depend on the surface orientation. Indeed, in the presence of one $\mathrm{CO}$ adsorbed on top of isolated Pd or bridging the Pd dimer, the Pd atoms become highly stable on the surface of the alloy with a noticeable preference for the (111) orientation (for isolated $\mathrm{Pd} E_{\text {seg }}=-0.23$ eV/atom and -0.42 eV/atom for (100) and (111) surface, respectively). This result shows that, if the ability of the Pd atoms to segregate on surface is controlled by the binding energy of the reactants, the binding energy is directly related to the "host" surface atomic structure of the alloy and its orientation. The calculated negative segregation values are consistent with the observed Pd surface enrichment upon $\mathrm{CO}$ exposure described in the experimental results, and predict that both Pd monomers and Pd dimers can exist on the top surface of alloy nanoparticles.

It is worth noting that the effect of $\mathrm{CO}$ on Pd segregation is stronger than that of oxygen. Indeed, we reported in a previous work [11], that in the presence of $\mathrm{O}_{2}$ molecules, the $\mathrm{Pd}$ monomer is as stable in the surface as in the bulk. In addition, for adsorbed atomic oxygen 
[10], the segregation of Pd was found to be oxygen coverage dependent since more than $1 / 3$ of a surface monolayer of $\mathrm{O}$ was necessary to induce $\mathrm{Pd}$ segregation.

\section{CO adsorption and stretching frequencies}

To facilitate the comparison between calculated and experimental vibration frequencies, we applied a scaling factor of 1.033 to adjust the calculated frequency of $\mathrm{CO}$ on atop $\mathrm{Pd}$ site of the $\mathrm{Pd}_{38}$ cluster to the value of $2077 \mathrm{~cm}^{-1}$, experimentally measured for $\mathrm{CO}$ linearly adsorbed on metallic Pd. Table 1 gathers the main features of $\mathrm{CO}$ adsorbed on $\mathrm{Au}_{38}$ and $\mathrm{Pd}_{38}$ clusters in terms of metal-CO distances, $\mathrm{CO}$ adsorption energies and corrected $v_{\mathrm{CO}}$ frequencies.

Table 1: DFT optimized configurations, CO-metal distances $\left(\mathrm{d}_{\mathrm{C}-\mathrm{Au}}\right.$ or $\left.\mathrm{Pd}\right), \mathrm{CO}$ adsorption energies $\left(\mathrm{E}_{\mathrm{ads}}\right)$ and corrected $\mathrm{vCO}$ frequencies on monometallic $\mathrm{Au}_{38}$ and $\mathrm{Pd}_{38}$ clusters.

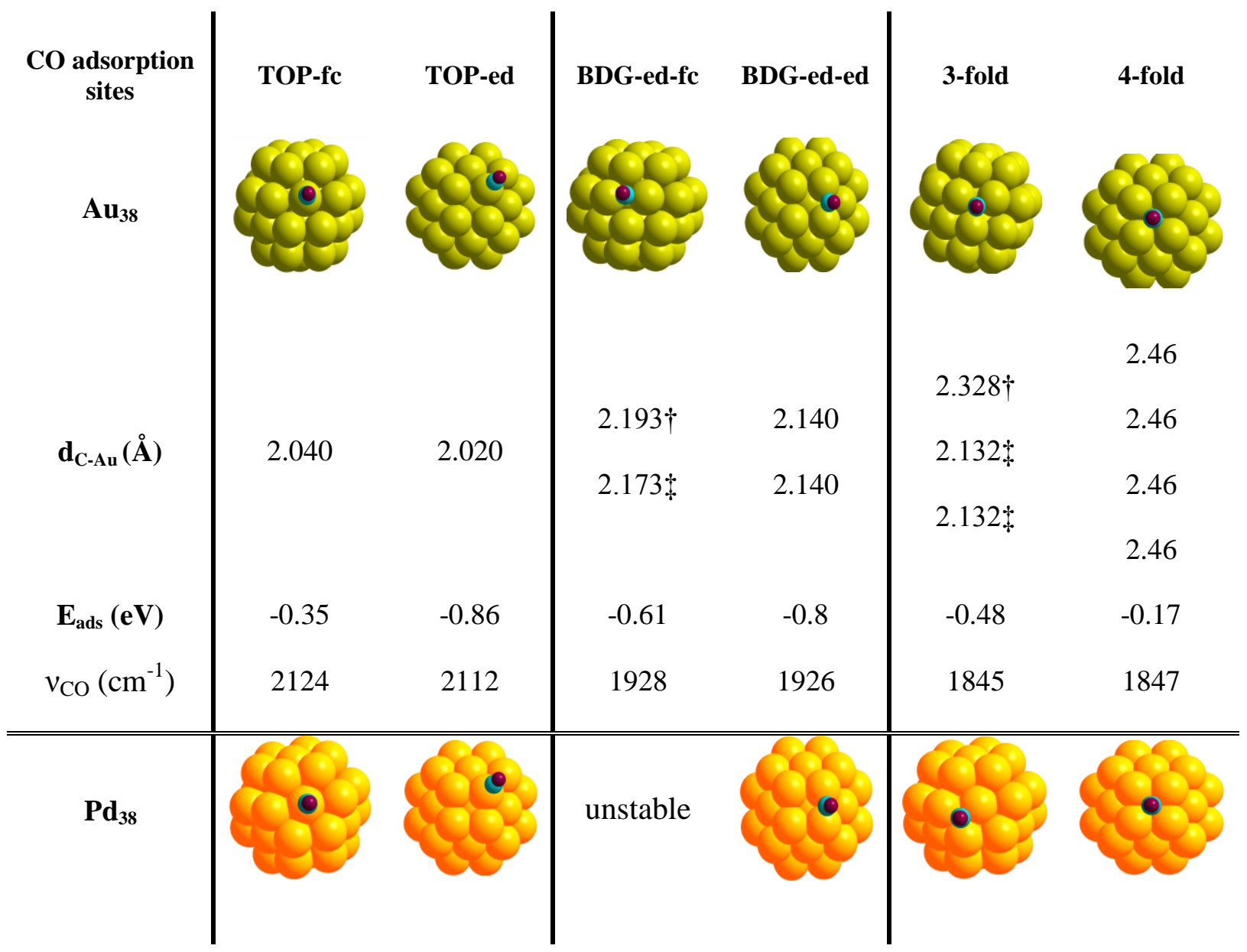




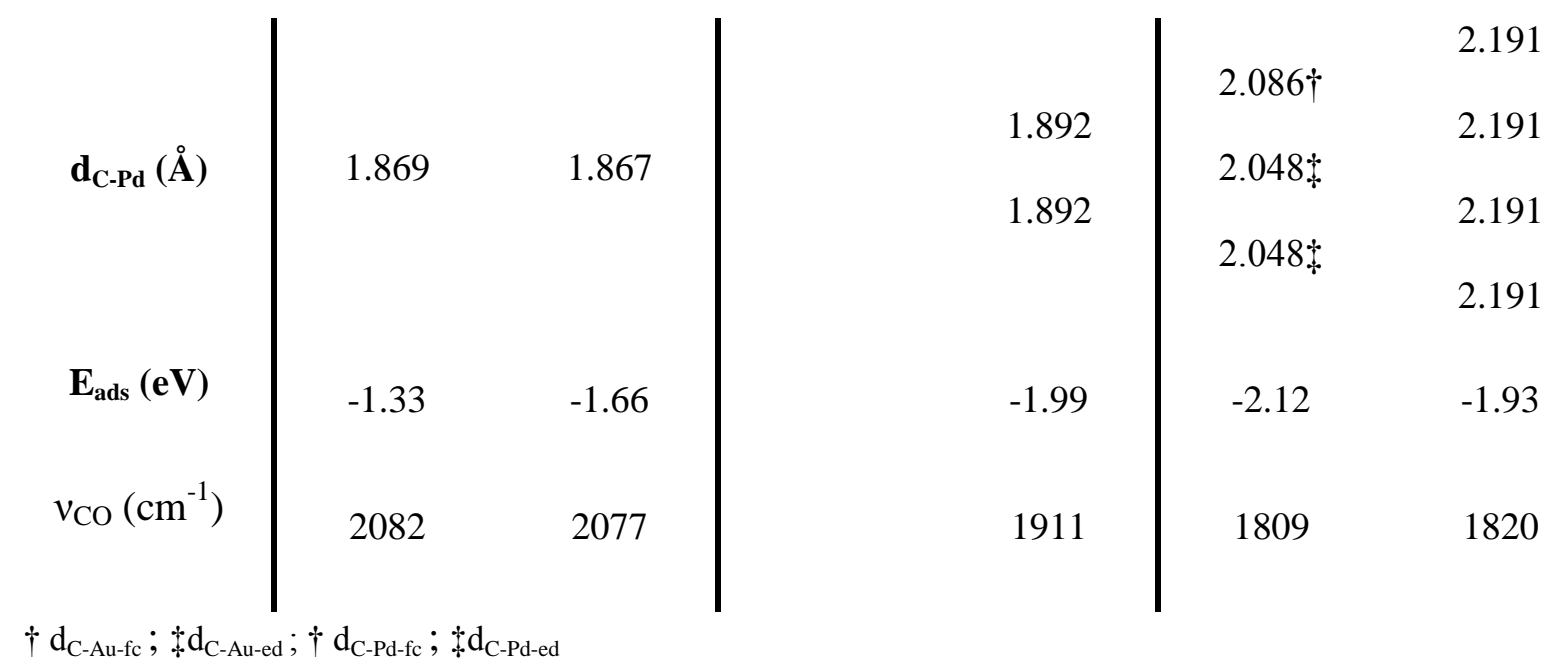

Monometallic gold and palladium clusters: As expected, on pure gold the most favorable CO adsorption site is the top-edge (TOP-ed) site, i.e., CO linearly adsorbed on an undercoordinated $\mathrm{Au}$ atom located in an edge site, with calculated adsorption energy of $-0.86 \mathrm{eV}$. The corresponding CO frequency is about $2112 \mathrm{~cm}^{-1}$, which matches well with the single IRband observed on gold clusters at $2104 \mathrm{~cm}^{-1}$. The adsorption of CO on a top-facet (TOP-fc) site whose coordination number is 9 is highly unfavorable. Furthermore, the 3 -fold gold site of the (111) facet and the 4-fold sites of the (100) facet are also unfavorable for CO adsorption.

On the (100) face composed of four low-coordinated Au atoms, a strong adsorption energy on the bridged edge-edge (BDG-ed-ed) site is also predicted $\left(E_{a d s}=-0.80 \mathrm{eV}\right)$. Although this type of favorable adsorption site was already predicted by other DFT studies [54, 55], no bridge adsorption of $\mathrm{CO}$ on pure gold has been observed experimentally. Indeed, one of the known artefacts of DFT calculations in close-packed metal surfaces is the overestimation of the adsorption energy for sites with high coordination compared to sites with low coordination (with our model cluster, we got similar energies for atop and bridging sites). This overestimation results from the underestimated energy difference between HOMO and 
LUMO orbitals that contributes to the CO overbinding. Different GGA functionals reduce these discrepancies, but neither harder potentials for CO, nor different GGA functionals correct the results for $\mathrm{CO}$ adsorption on these substrates [55].

In contrast to the case of the gold cluster, $\mathrm{CO}$ prefers to occupy the 3 -fold site of the (111) facet of the palladium cluster with a strong adsorption energy of $-2.12 \mathrm{eV}$. The 4-fold and BDG-ed-ed sites of the (100) facet are also favorable sites with calculated adsorption energies of -1.93 and $-1.99 \mathrm{eV}$, respectively. For these three types of sites, the calculated $\mathrm{CO}$ stretching frequencies are 1809,1820 and $1911 \mathrm{~cm}^{-1}$, respectively. These values fall within the wavenumber range of the broad IR band observed around $1910 \mathrm{~cm}^{-1}$ in the $\mathrm{Pd} / \mathrm{Al}_{2} \mathrm{O}_{3}$ sample (Figure 1). The adsorption of $\mathrm{CO}$ on atop $\mathrm{Pd}$ is also exothermic with a strong preference for the under coordinated site, TOP-ed site $(-1.66 \mathrm{eV})$, rather than TOP-fc site ($1.33 \mathrm{eV})$. Compared to gold, adsorbed carbon monoxide exhibits bands at lower frequency on palladium atoms and the adsorption energies are two or three time higher.

Table 2: DFT optimized configurations, CO-metal distances, $\mathrm{CO}$ adsorption energies and corrected $v \mathrm{CO}$ frequencies on $\mathrm{Au}_{37} \mathrm{Pd}_{1}$ nanoalloy cluster

\begin{tabular}{|c|c|c|c|c|}
\hline $\mathbf{A u}_{37} \mathbf{P d}_{1}\left(\mathbf{e d}_{\mathbf{P d}}\right)$ & TOP-ed $_{P d}$ & TOP-fc $c_{\mathrm{Au}}$ & BDG-ed $_{\mathrm{Pd}^{-}}-\mathrm{ed}_{\mathrm{Au}}$ & BDG-ed $_{P d}-f_{\mathrm{Au}}$ \\
\hline Configurations & & & & \\
\hline $\mathbf{d}_{\mathrm{C}-\mathbf{M}(\mathbf{M}: \mathbf{A u}, \mathbf{P d})}(\mathbf{\AA})$ & 1.915 & 2.011 & $\begin{array}{c}2.24 * \\
1.988 * * \\
\end{array}$ & $\begin{array}{c}2.178 * \\
1.990^{* *}\end{array}$ \\
\hline $\mathbf{E}_{\text {ads }}(\mathbf{e V})$ & -1.40 & -0.32 & -1.06 & -0.91 \\
\hline$v_{\mathrm{CO}}\left(\mathrm{cm}^{-1}\right)$ & 2094 & 2139 & 1969 & 1960 \\
\hline $\mathbf{A u}_{37} \mathbf{P d}_{1}\left(\mathbf{f c}_{\mathbf{P d}}\right)$ & TOP-fcPd & TOP-ed $_{A u}$ & BDG-ed $d_{\mathrm{Au}}-\mathrm{ed}_{\mathrm{Au}}$ & BDG-ed $_{\mathrm{Au}}-\mathbf{f c}_{\mathbf{P d}}$ \\
\hline Configurations & & & & \\
\hline
\end{tabular}




\begin{tabular}{|c|c|c|c|c|}
\hline $\mathbf{d}_{\mathrm{C}-\mathrm{M}(\mathrm{M}: \mathrm{Au}, \mathbf{P d})}(\mathbf{A})$ & 1.922 & 1.972 & $\begin{array}{l}2.135 \\
2.135\end{array}$ & $\begin{array}{c}2.415^{*} \\
1.953^{* *}\end{array}$ \\
\hline $\mathbf{E}_{\text {ads }}(\mathbf{e V})$ & -1.00 & -0.81 & -0.68 & -0.72 \\
\hline $\mathbf{v}_{\mathbf{C O}}\left(\mathbf{c m}^{-1}\right)$ & 2083 & 2122 & 1932 & 1934 \\
\hline
\end{tabular}

$* \mathrm{~d}_{\mathrm{C}-\mathrm{Au}} ; * * \mathrm{~d}_{\mathrm{C}-\mathrm{Pd}}$

Nanoalloy clusters: A wide variety of $\mathrm{CO}$ adsorption sites in the two nanoalloy models $\left(\mathrm{Au}_{37} \mathrm{Pd}_{1}\right.$ and $\mathrm{Au}_{36} \mathrm{Pd}_{2}$ clusters) with different surface configurations of Pd monomer (Table 2) and dimer (Table 3) was investigated.

Table 3: DFT optimized configurations, CO-metal distances, adsorption energies and corrected $v \mathrm{CO}$ frequencies on $\mathrm{Au}_{36} \mathrm{Pd}_{2}$ nanoalloy cluster

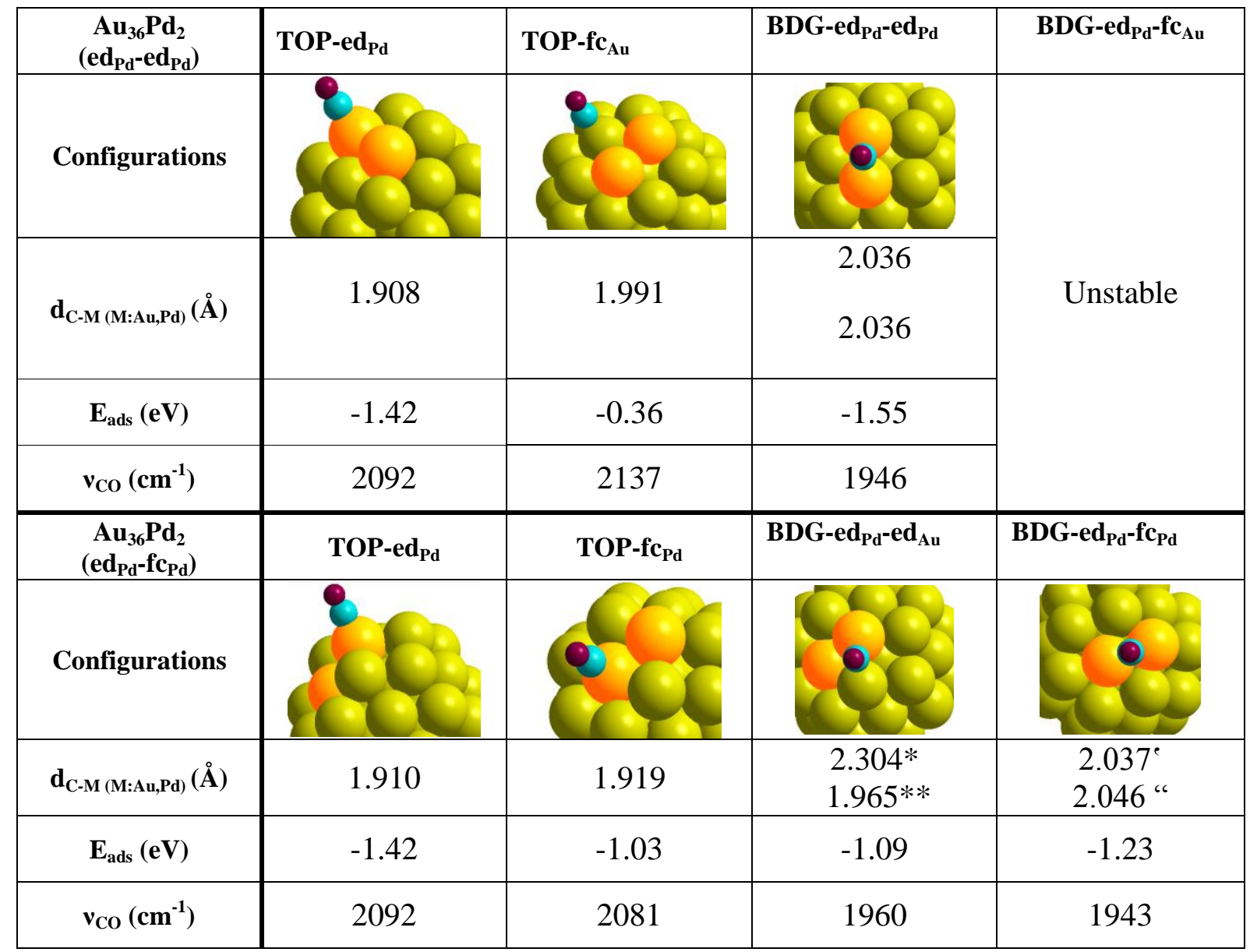

$* \mathrm{~d}_{\mathrm{C}-\mathrm{Au}} ; * * \mathrm{~d}_{\mathrm{C}-\mathrm{Pd}} ;{ }^{\circ} \mathrm{d}_{\mathrm{C}-\mathrm{Pd}-\mathrm{ed}} ;{ }^{\prime} \mathrm{d}_{\mathrm{C}-\mathrm{Pd}-\mathrm{fc}}$ 


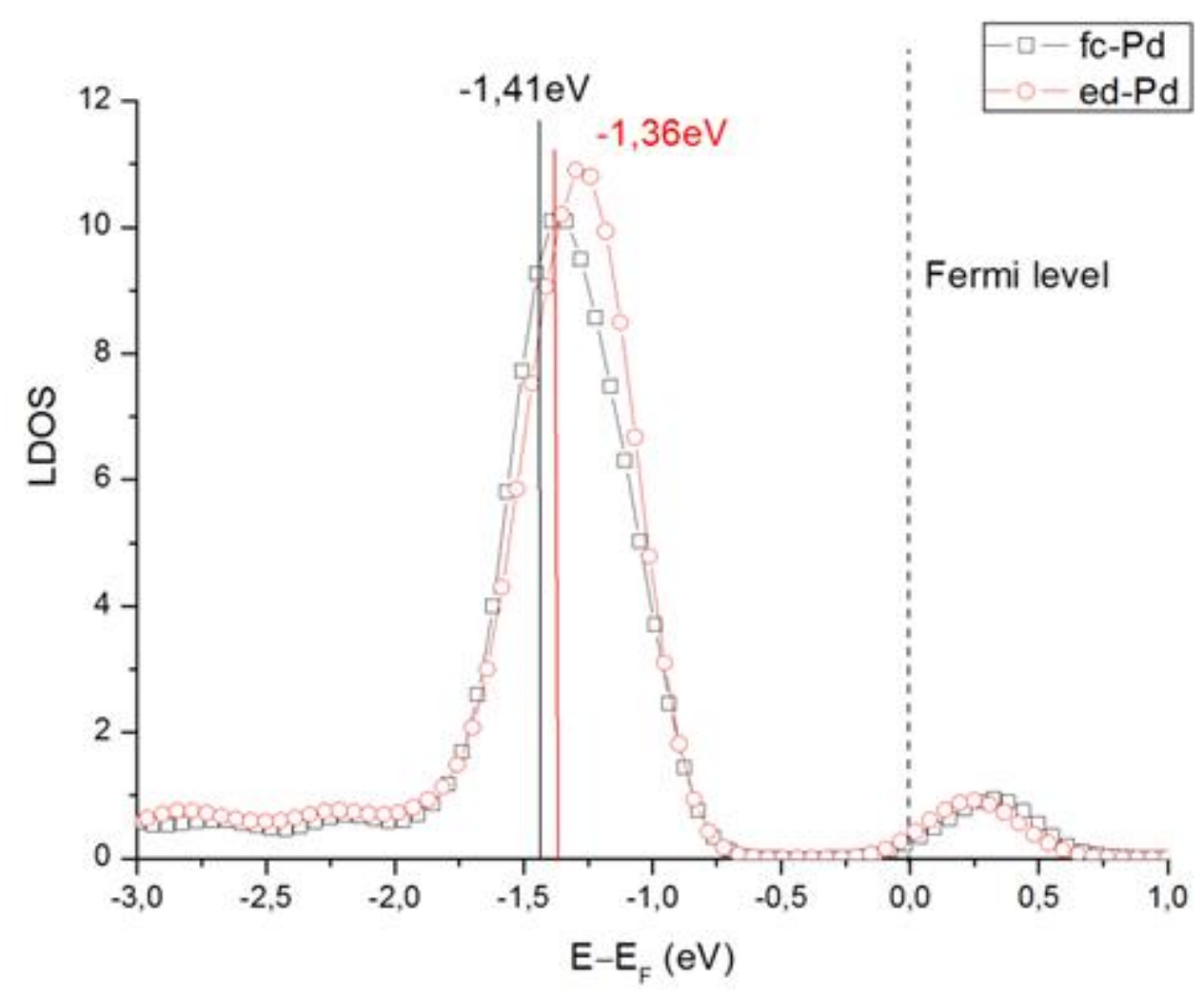

Figure 4: 4d-bands DOS for the Pd atoms located at edge (circle) and facet (square) sites of the $\mathrm{Au}_{37} \mathrm{Pd}_{1}$ cluster.

For the $\mathrm{Au}_{37} \mathrm{Pd}_{1}$ cluster, two Pd monomer locations were considered: Pd at edge site $\left(e d_{P d}\right)$ and $\mathrm{Pd}$ on facet site $\left(\mathrm{fc}_{\mathrm{Pd}}\right)$. Among all computed configurations, the top Pd atom is the preferred adsorption site for $\mathrm{CO}$ compared to adsorption over $\mathrm{Au}$ atoms or bridging $\mathrm{Au}-\mathrm{Pd}$ sites. Moreover, the preferred top Pd site is predominantly a Pd edge site (TOP-ed $\left.\mathrm{Pd}_{\mathrm{Pd}}\right)(-1.4$ $\mathrm{eV})$ rather than $\mathrm{Pd}$ on the facet $\left(\mathrm{TOP}-\mathrm{fc}_{\mathrm{Pd}}\right)(-1.0 \mathrm{eV})$. This reveals an effect of the $\mathrm{Pd}$ coordination number on the $\mathrm{CO}$ interaction with the nanoalloy surface. Figure 4 shows the Local Density Of State (LDOS) of the d-bands of Pd atoms at edge $\left(\mathrm{ed}_{\mathrm{Pd}}\right)$ and on facet $\left(\mathrm{fc}_{\mathrm{Pd}}\right)$ in $\mathrm{Au}_{37} \mathrm{Pd}_{1}$ cluster. It can be seen that the $\mathrm{ed}_{\mathrm{Pd}} \mathrm{d}$-band is slightly shifted to the Fermi level with a calculated band center at $-1.36 \mathrm{eV}$ compared to $-1.41 \mathrm{eV}$ for $\mathrm{fc}_{\mathrm{Pd}} \mathrm{d}$-band. According to the Nørskov theory on the adsorption of CO on metals [56], the observed shifts in the d-band centers towards the Fermi level can be correlated with the increase of the adsorption energy of $\mathrm{CO}$ from $\mathrm{Pd}$ facet to edge sites. The corrected harmonic frequencies of $\mathrm{CO}$ on $\mathrm{TOP}-\mathrm{fc}_{\mathrm{Pd}}$ and 
TOP-ed $d_{P d}$ sites are 2083 and $2094 \mathrm{~cm}^{-1}$, respectively. This result shows that the decrease in the coordination number of $\mathrm{Pd}$ in $\mathrm{Au}_{37} \mathrm{Pd}_{1}$ alloy cluster (from $9 \mathrm{Au}$ neighbors to 6) induces a blue shift in the $\mathrm{CO}$ stretching by more than $10 \mathrm{~cm}^{-1}$. This could explain the multiple components of the band of $\mathrm{CO}$ linearly adsorbed on $\mathrm{Pd}$ atoms in the $\mathrm{Au}-\mathrm{Pd}(20) / \mathrm{Al}_{2} \mathrm{O}_{3}$ sample (2076, 2062 and $2043 \mathrm{~cm}^{-1}$ ) (Figure 2) and allow to assign the slight blue shift from 2043 toward $2077 \mathrm{~cm}^{-1}$ to the decreasing number of gold neighbors around palladium when palladium segregates to the surface and occupies low coordinated sites. The DFT optimization of the geometry also predicts that the bridge BDG-ed $\mathrm{Pd}_{\mathrm{Pd}}-\mathrm{ed}_{\mathrm{Au}}$ site is a favorable site for $\mathrm{CO}$ adsorption. On this site, the $\mathrm{CO}$ molecule, that tends to make short bonds with $\mathrm{Pd}$ atom, vibrates with a frequency value of $1969 \mathrm{~cm}^{-1}$. This value may correspond to the observed IR band at $1950 \mathrm{~cm}^{-1}$ whose intensity increases upon CO adsorption (Figure 2).

The adsorption energy of $\mathrm{CO}$ on a TOP-ed Au $_{\text {site }}$ with a $\mathrm{Pd}$ atom as a neighbor $(-0.81 \mathrm{eV}$, Table 2) is similar to the one estimated for the same site on the monometallic $\mathrm{Au}_{38}$ cluster ($0.86 \mathrm{eV}$, Table 1); this seems to indicate that the presence of isolated $\mathrm{Pd}$ has a limited influence on the electronic properties of gold neighbors.

The adsorption of $\mathrm{CO}$ on $\mathrm{Pd}$ dimers was studied using the $\mathrm{Au}_{36} \mathrm{Pd}_{2}$ cluster. The $\mathrm{Pd}$ dimer was located at the edge-edge site and at the edge-facet site (Table 3). As in the case of the Pd monomer $\left(\mathrm{Au}_{37} \mathrm{Pd}_{1}\right.$ cluster $), \mathrm{CO}$ prefers to interact with $\mathrm{Pd}$ atoms rather than with $\mathrm{Au}$ atoms. In the presence of Pd dimer, the bridge BDG-ed ${ }_{\mathrm{Pd}}-\mathrm{ed}_{\mathrm{Pd}}$ site is predicted to be the most favorable site for $\mathrm{CO}$ adsorption with an energy of $-1.55 \mathrm{eV}$. This value is $0.44 \mathrm{eV}$ lower than the adsorption energy value of $\mathrm{CO}$ over the equivalent site in pure $\mathrm{Pd}$ cluster and $0.75 \mathrm{eV}$ higher than on pure gold. However, the preferred adsorption of $\mathrm{CO}$ on bridging Pd dimer sites seems to depend on the coordination number of the palladium atoms. Indeed, whereas BDG$\mathrm{ed}_{\mathrm{Pd}}-\mathrm{fc}_{\mathrm{Pd}}$ site $(-1.23 \mathrm{eV})$ is more favorable for $\mathrm{CO}$ adsorption than TOP-fc $\mathrm{Pd}_{\mathrm{Pd}}$ site $(-1.03 \mathrm{eV})$ in the $\mathrm{Au}_{36} \mathrm{Pd}_{2}$ cluster, it is less stable than the TOP-ed $\mathrm{Pd}_{\mathrm{P}}$ site $(-1.42 \mathrm{eV})$. Hence, although $\mathrm{CO}$ 
tends to interact with a maximum of $\mathrm{Pd}$ atoms and form bridged $\mathrm{CO}$ in pure $\mathrm{Pd}$ clusters, it prefers to adsorb on the top of under-coordinated isolated or contiguous Pd sites in AuPd alloy clusters.

The computed vibration frequencies of CO adsorbed on BDG-ed $\mathrm{Pd}^{-}-\mathrm{d}_{\mathrm{Pd}}$, BDG-ed $\mathrm{Pd}_{\mathrm{Pd}}-\mathrm{ed} \mathrm{Au}_{\mathrm{Au}}$ and BDG-ed $\mathrm{Pd}_{\mathrm{Pd}}-\mathrm{fc}_{\mathrm{Pd}}$ sites were found at 1946,1960 and $1943 \mathrm{~cm}^{-1}$, respectively. They could correspond to the observed IR components at 1950 and $1927 \mathrm{~cm}^{-1}$ in the DRIFT spectrum of $\mathrm{Au}-\mathrm{Pd}(20) / \mathrm{Al}_{2} \mathrm{O}_{3}$ (Figure 2). Let us add that the calculated adsorption of $\mathrm{CO}$ on 3 -fold and 4fold Pd sites is not favorable and could only exist over larger surface Pd ensembles. As no IR band is observed in the region assigned to these latter adsorption sites $\left(\approx 1800 \mathrm{~cm}^{-1}\right)$, the presence of large Pd ensembles on the surface of our nanoparticles could be ruled out.

From these DFT calculation results, we can tentatively assigned the various bands observed in the DRIFTS spectra of the $\mathrm{AuPd} / \mathrm{Al}_{2} \mathrm{O}_{3}$ catalyst to linear $\mathrm{CO}$ on $\mathrm{ed}_{\mathrm{Au}}\left(2110 \mathrm{~cm}^{-1}\right.$ (DRIFTS) / $\left.2122 \mathrm{~cm}^{-1}(\mathrm{DFT})\right)$, linear CO on ed $\mathrm{Pd}_{\mathrm{Pd}}\left(2076 \mathrm{~cm}^{-1} / 2094 \mathrm{~cm}^{-1}\right)$, linear CO on fc $\mathrm{Pd}_{\mathrm{Pd}}\left(2062 \mathrm{~cm}^{-1} /\right.$ $\left.2083 \mathrm{~cm}^{-1}\right)$, bridge $\mathrm{CO}$ on ed $\mathrm{Pd}^{-} \mathrm{ed}_{\mathrm{Au}}\left(1950 \mathrm{~cm}^{-1} / 1969 \mathrm{~cm}^{-1}\right)$ and bridge $\mathrm{CO}$ on $\mathrm{ed}_{\mathrm{Pd}^{-}} \mathrm{ed}_{\mathrm{Pd}}$ or $\mathrm{ed}_{\mathrm{Pd}}-\mathrm{fc}_{\mathrm{Pd}}\left(1927 \mathrm{~cm}^{-1} / 1946\right.$ or $\left.1943 \mathrm{~cm}^{-1}\right)$. The assignment of the minor component of the linear CO on Pd in the DRIFT spectra at $2043 \mathrm{~cm}^{-1}$ was however not clear. Let us note that according to the work of García-Mota et al. [57] on the multiple CO adsorption on Au-Pd alloy system, the vibrational frequencies are shown to resemble those of isolated molecule split by about $30 \mathrm{~cm}^{-1}$ due to the dipole-dipole interactions.

Electronic and energetic analysis of Pd distribution on the AuPd nanoparticle surface in the presence of $\mathrm{CO}$

In order to gain insight into the electronic structure of AuPd nanoalloy and to analyze the effect of $\mathrm{CO}$ interaction on the energetic stability of specific Pd ensembles on the surface of the nanoparticles, we investigated the change of charge distribution before and after $\mathrm{CO}$ 


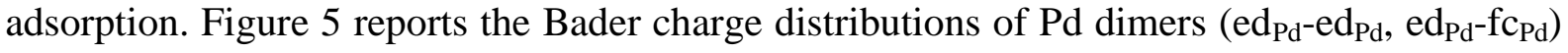
in $\mathrm{Au}_{36} \mathrm{Pd}_{2}$ clusters. Under vacuum, palladium at edge sites $\left(\mathrm{ed}_{\mathrm{Pd}}\right)$ are weakly positively charged $(\approx+0.04 \mathrm{e})$ in contrast to $\mathrm{Pd}$ in facet sites $\left(\mathrm{fc}_{\mathrm{Pd}}\right)$ whose charge is of $+0.11 \mathrm{e}$. This could partially explain the energetic stability of Pd in high coordinated sites under vacuum. A more important point is that the positive charge of $\mathrm{Pd}$ significantly increases when $\mathrm{CO}$ is adsorbed on it (up to +0.22 e for bridge $\mathrm{CO}$ adsorption and +0.19 e for top $\mathrm{CO}$ adsorption). These results provide evidence of back-donation from Pd to CO. Indeed, the nature of the adsorption bond between $\mathrm{CO}$ and d-metal surfaces is conventionally understood in terms of the $5 \sigma \mathrm{CO}$ donation to the metal associated with a back-donation to the empty $2 \pi^{*} \mathrm{CO}$ orbital $[58,59]$. Here, the strong increase of the positive charge of $\mathrm{Pd}$ when interacting with $\mathrm{CO}$, particularly of the $\mathrm{Pd}$ edge sites, indicates preponderant $\pi$-back-donation from undercoordinated $\mathrm{Pd}$ to $\mathrm{CO}$. This fact explains the strong $\mathrm{CO}$ adsorption energies calculated on such sites and therefore the high energetic stability of Pd on edges in the presence of $\mathrm{CO}$ gas.

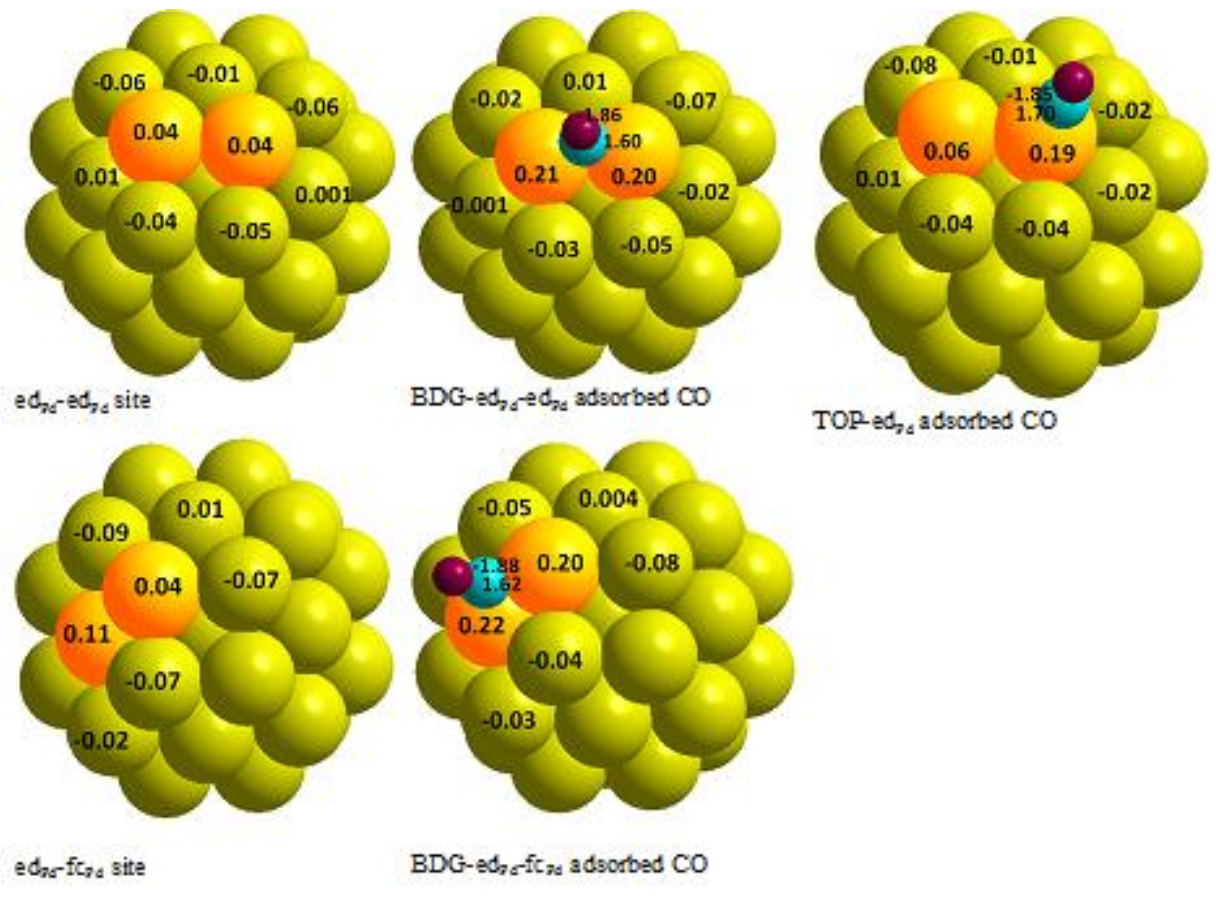

Figure 5: Bader charge distribution on $\mathrm{Pd}_{2} \mathrm{Au}_{36}$ alloy system before and after $\mathrm{CO}$ adsorption. 


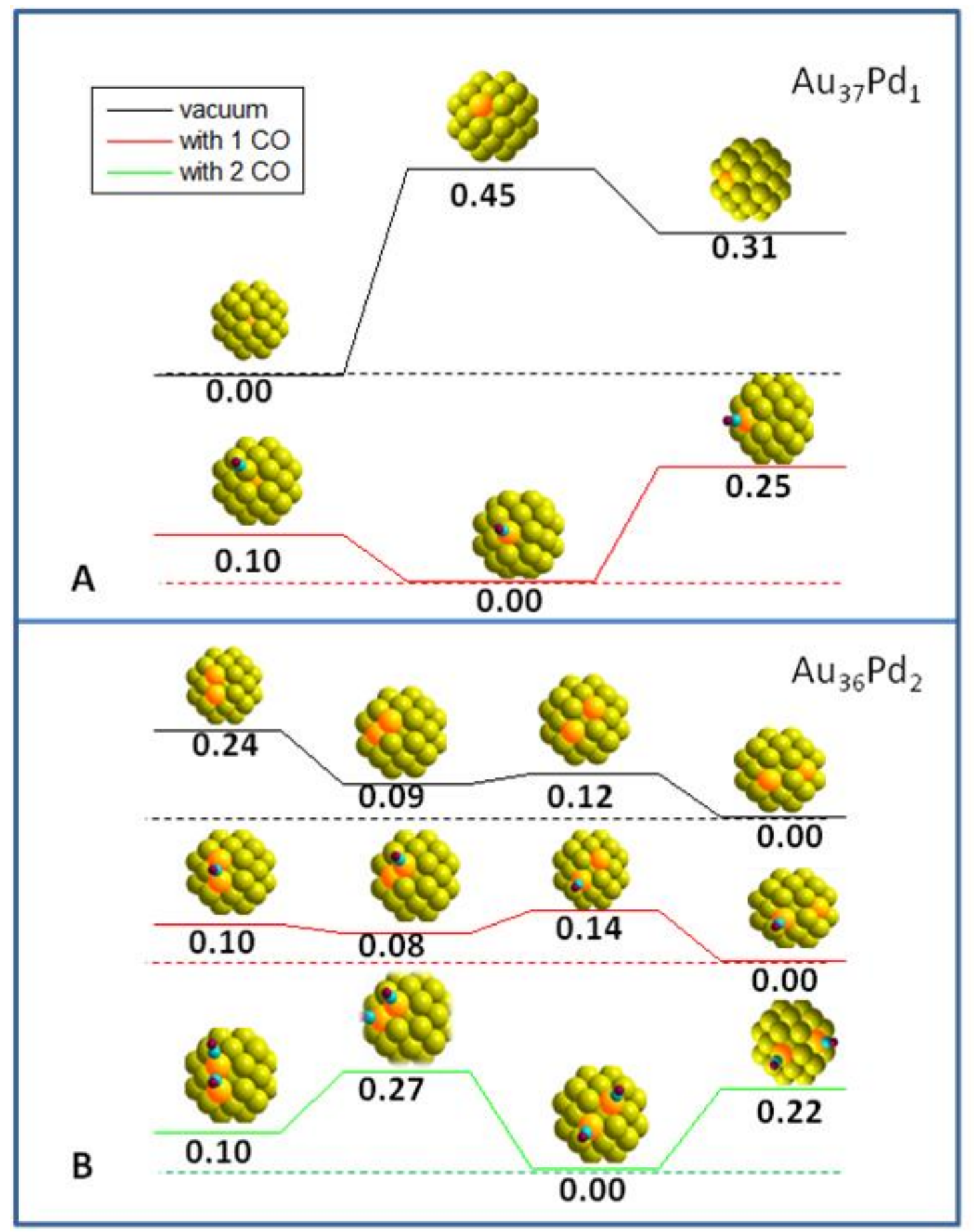

Figure 6: Evolution of energetic stability of different configurations of Pd before and after $\mathrm{CO}$ adsorption. The bold values represent energy difference (eV/atom) with respect to the most stable structure $(0.00 \mathrm{eV} /$ atom $)$ of each calculated case: (A) $\mathrm{Au}_{37} \mathrm{Pd}_{1}, \mathrm{CO}-\mathrm{Au}_{37} \mathrm{Pd}_{1} ;(\mathrm{B})$ $\mathrm{Au}_{36} \mathrm{Pd}_{2}, \mathrm{CO}-\mathrm{Au}_{36} \mathrm{Pd}_{2}, 2 \mathrm{CO}-\mathrm{Au}_{36} \mathrm{Pd}_{2}$. 
In addition, to rationalize the changes induced by $\mathrm{CO}$ adsorption on $\mathrm{Pd}$ surface distribution, we compared (see Figure 6) the energetic stability of different Au-Pd systems interacting or not with adsorbed $\mathrm{CO}$. Figure 6A represents the energy diagram (calculated with respect to the lowest total energy structure) of different configurations of $\mathrm{Au}_{37} \mathrm{Pd}_{1}$ alloy. Under vacuum, the energetic stability of the configuration in which Pd is located in the bulk cluster is larger than that of $\mathrm{Pd}$ on edge or facet by $0.45 \mathrm{eV}$ and $0.31 \mathrm{eV}$, respectively. Again, Pd is found to be more stable in the core than on the cluster surface and the computed segregation energies $\{\mathrm{E}$ (system with $\mathrm{Pd}$ in the bulk)-E(system with $\mathrm{Pd}$ on the surface) $\}$ are comparable to the values obtained on (100) and (111) surfaces $\left(E_{s e g}=+0.42 \mathrm{eV}\right.$ and $+0.39 \mathrm{eV}$, respectively). After $\mathrm{CO}$ adsorption, the configuration in which $\mathrm{Pd}$ occupies edge site becomes the most stable one. This predicts that under $\mathrm{CO}$ pressure, Pd tends to substitute undercoordinated $\mathrm{Au}$ atoms located at the edges of the nanoparticles. Freund and coworkers [43] performed DFT studies on the segregation of Pd monomer on $\mathrm{Au}(221)$ surface and reported that upon adsorption of $\mathrm{CO}$, the preferred position of Pd switches from the bottom of the edge site (over-coordinated) to the top edge (under-coordinated) site.

For clusters containing two Pd atoms (Figure 6B), we considered one Pd at the edge position and we compared several configurations for the second Pd atom on the surface. Although not exhaustive, this analysis gives interesting trends. First of all and as expected, under vacuum the second Pd atom prefers to occupy high coordinated sites (facet) rather than edge sites. In addition, the comparison of the energetic stability of different Pd locations (ed-fc or ed-ed) seems to suggest that the configurations with contiguous Pd atoms are highly unfavorable, especially on edge sites $(+0.24 \mathrm{eV})$. Using DFT calculations on $\operatorname{AuPd}(111)$ and (100) surfaces, Russo et al. have already reported that Pd atoms tend to be surrounded by Au atoms as first neighbors and that Pd second neighbors may exist [60]. In the presence of one adsorbed CO molecule, this tendency seems to remain true in spite of the decrease of the 
ordering stability. Indeed, the configuration in which CO linearly interacts with the edge Pd site while the other $\mathrm{fc}_{\text {-Pd }}$ site is free from $\mathrm{CO}$, is now only $0.1 \mathrm{eV}$ more favorable than $\mathrm{CO}$ bridging contiguous edge Pd atoms. However, even though DFT total energy calculations predicted the configuration of $\mathrm{ed}_{\mathrm{Pd}}-\mathrm{ed}_{\mathrm{Pd}}$ dimer as slightly instable, this configuration could exist since the IR spectrum of $\mathrm{AuPd} / \mathrm{Al}_{2} \mathrm{O}_{3}$ reveals the signature of $\mathrm{CO}$ bridging such $\mathrm{Pd}$ ensemble (IR band appearing at $1950 \mathrm{~cm}^{-1}$ ) during the first stage of CO exposure (Figure 1). With increasing $\mathrm{CO}$ coverage (1 $\mathrm{CO}$ for each $\mathrm{Pd}$ ), the most stable configurations become those where the two Pd atoms occupy the edge sites with a slight preference for the configuration where $\mathrm{Pd}$ are second neighbors.

The overall trends obtained in these DFT calculations indicate that Pd segregating on surface of AuPd bimetallic particles preferentially migrates towards edge positions upon $\mathrm{CO}$ exposure. This appears in agreement with the experimental DRIFT data, which show that the band assigned to linear $\mathrm{CO}$ on $\mathrm{ed}_{\mathrm{Pd}}\left(2076 \mathrm{~cm}^{-1}\right)$ is the one which increases the most with time under $\mathrm{CO} / \mathrm{He}$. Moreover, the continuous intensity increase of this band seems to occur at the expense of the one of $\mathrm{CO}$ adsorbed on $\operatorname{ed}_{\mathrm{Au}}\left(2110 \mathrm{~cm}^{-1}\right)$, underlining the progressive replacement of Au by $\mathrm{Pd}$ at the edge sites of the particles.

The substitution of Au atoms by $\mathrm{Pd}$ at the edges of the bimetallic particles may induce deep modifications of the reactivity of bimetallic Au-Pd catalysts, especially regarding the $\mathrm{CO}$ oxidation reaction. Indeed, the low coordination sites (edges and corners) of supported $\mathrm{Au}$ nanoparticles are usually considered as the active sites in $\mathrm{CO}$ oxidation, at least as the adsorption sites of CO [39]. In a very recent study by Environmental Transmission Electron microscopy (ETEM) and DRIFTS, we showed that the AuPd bimetallic particles in $\mathrm{Au}-$ $\mathrm{Pd} / \mathrm{TiO}_{2}$ catalyst rapidly restructured under $\mathrm{CO} / \mathrm{O}_{2}$ reaction conditions, leading to a fast decrease of the catalytic conversion of $\mathrm{CO}$ to $\mathrm{CO}_{2}$ [12]. The loss of activity was attributed, but not demonstrated, to the replacement of $\mathrm{Au}$ atoms by $\mathrm{Pd}$ at the edge sites of the particles 
which is in accordance with the results discussed in the present work. Although some studies indicated that the catalytic activity in $\mathrm{CO}$ oxidation was enhanced by the segregation of $\mathrm{Pd}$ at the surface of the AuPd alloy, this beneficial effect was only observed for model AuPd(100) surfaces $(\mathrm{Au}: \mathrm{Pd}=1: 1)[14,47]$ and $\mathrm{Pd}-\mathrm{Au}$ particles grown on $\mathrm{TiO}_{2} / \mathrm{Mo}(110)$ [6]. Owing to the absence of low coordination sites on the $\mathrm{Au}(100)$ surface, the latter did not present any activity in $\mathrm{CO}$ oxidation and the increase of the $\mathrm{CO}$ conversion rate on $\mathrm{AuPd}(100)$ was related to the presence of contiguous $\mathrm{Pd}$ ensembles involved in the dissociation of $\mathrm{O}_{2}[14,47]$. In the case of supported AuPd nanoparticles in real catalysts, usually containing low $\mathrm{Au} / \mathrm{Pd}$ atomic ratio, no synergetic effect was demonstrated between $\mathrm{Au}$ and $\mathrm{Pd}$ in $\mathrm{CO}$ oxidation [61-62]. The formation of AuPd alloy in bimetallic catalysts with high Pd content (low $\mathrm{Au} / \mathrm{Pd}$ ratio) was even proposed to be unfavourable to achieve high activity in $\mathrm{CO}$ oxidation [63]. These observations could be interpreted on the basis of our DFT and experimental results revealing the preferential segregation of Pd at the edge positions in bimetallic AuPd nanoparticles on which $\mathrm{CO}$ will be too strongly adsorbed to react with oxygen at RT; this could explain the lower activity of AuPd catalyst compared to Au catalysts in $\mathrm{CO}$ oxidation.

This work underlines the determining contribution that theoretical calculations could bring to the understanding of the observations made by in situ or operando techniques. As presented in a recent review [64], the combination of experimental and theoretical data allows extending the comprehension of the surface state of metallic nanoparticles under reaction conditions. This is of particular importance in the case of multi-metallic catalysts for which reactantdriven changes of the surface composition may occur. 


\section{Conclusion}

Combined first-principles total energy calculations and DRIFTS studies were carried out to investigate the location of the $\mathrm{Pd}$ atoms in $\mathrm{Au}-\mathrm{Pd}$ nano-particles where $\mathrm{Au} / \mathrm{Pd} \gg>1$ when $\mathrm{CO}$ was adsorbed. Evidences for Pd surface enrichment due to the strong adsorption with $\mathrm{CO}$ are reported. Based on the calculation of the $\mathrm{CO}$ frequencies and IR experimental assignments only isolated palladium and dimer of palladium atoms were found to exist on the surface. This means that no Pd aggregation could happen and no Pd islands within the surface layer could be formed. In addition, the calculations allowed attributing the observed multi component IR band related to $\mathrm{CO}$ on top $\mathrm{Pd}$ atoms to $\mathrm{CO}$ adsorbed on top of both low and high coordinated palladium sites. Similarly, two new types of bridge CO sites, Au-Pd and Pd-Pd, were identified in the broad band of bridge CO. Finally, from energetic and electronic analysis, one could predict that, when reactive gas containing $\mathrm{CO}$ is exposed to the surface under conditions where migration and restructuring can occur, Pd will migrate toward the edge positions on small AuPd nanoparticles. This information of the structural and atomic arrangement of Au-Pd nanalloys under reacting gas is crucial to explain that $\mathrm{Pd}$ in $\mathrm{AuPd}$ catalysts inhibits the reaction of $\mathrm{CO}$ oxidation at $\mathrm{RT}$.

Acknowledgment: The authors acknowledge the support of the French Agence Nationale de la Recherche (ANR) under reference ANR- 11-JS07-0007 and EU (COST-MP0903). This work was granted access to the HPC resources of [CCRT/CINES/IDRIS] under the allocation 2012 [x2012086395] made by GENCI (Grand Equipement National de Calcul Intensif]. The authors thank Nicole Audiffren from the CINES for her availability and continuous help. 


\section{References:}

[1] G. Ertl, M. Neumann, K.M. Streit, Surf. Sci. 64 (1977) 393.

[2] O. Cairon, H. Guesmi, Phys. Chem. Chem. Phys. 13 (2011) 11430.

[3] P. Landon, P.J. Collier, A.F. Carley, et al. Phys. Chem. Chem. Phys. 5 (2003) 1811.

[4] D. Kumar, M.S. Chen, D.W. Goodman, Catal. Today 123 (2007) 77.

[5] M. García-Mota, N. Lopez, J. Am. Chem. Soc. 130 (2008) 14406.

[6] F. Gao, Y. Wang, D. W. Goodman, J. Phys. Chem. C 114 ( 2010) 4036.

[7] V. Soto-Verdugo, H. Metiu, Surf. Sci. 601 (2007) 5332.

[8] A. Hugon, L. Delannoy, J.M. Krafft, C. Louis, J. Phys. Chem. C 114 (2010) 10823.

[9] T.V. de Bocarme, M. Moors, N. Kruse, et al., Ultramicroscopy 109 (2009) 619.

[10] H. Guesmi, C. Louis, L. Delannoy, Chem. Phys. Lett. 503 (2011) 97.

[11] Dhouib, H. Guesmi, Chem. Phys. Lett. 521 (2012) 98.

[12] L. Delannoy, S. Giorgio, J.G. Mattei, et al. DOI : 10.1002/cctc.201200618 (2013).

[13] Ismail et al. J. Phys. Chem. C, 117 (2013) 293.

[14] F. Gao, Y. Wang, D. W. Goodman, J. Am. Chem. Soc. 131 (2009) 5734.

[15] R. Ferrando, J. Jellinek, R. L. Johnston, Chem. Rev. 108 (2008) 845.

[16] F. Lequien, J. Creuze, F. Berthier, et al. Phys. Rev. B 78 (2008) 075414.

[17] L. Delfour, J. Creuze, B. Legrand, Phys. Rev. Lett 103 (2009) 205701.

[18] F. Baletto, C. Mottet, R. Ferrando, Phys. Rev. Lett. 90 (2003) 135504.

[19] F. Tielens, J. Andrés, J. Phys. Chem. C 111 (2007) 10342.

[20] M. Mavrikakis, P. Stoltze, J.K. Nørskov, Catal. Lett. 64 (2000) 101.

[21] I.V. Yudanov, K.M. Neyman, Phys. Chem. Chem. Phys. 12 (2012) 5094. N. El Kolli, L. Delannoy, C. Louis, J. Catal. 297 (2013) 79. P.S. West, R.L. Johnston, et al. J. Phys. Chem. C 114 (2010) 19678. G. Kresse, J. Hafner, Phys. Rev. B 47 (1993) 558. J. P. Perdew, Y. Wang, Phys. Rev. B 45 (1992) 13244. P. E. Blochl, O. Jepsen, O.K. Andersen, Phys. Rev. B 49 (1994) 16223. G. Kresse, D. Joubert, Phys. Rev. B 59 (1999) 1758. Kittel, Introduction to Solid State Physics, seventh edn., Wiley, New York (1996). E. Aprá, F. Baletto, et al. Phys. Rev. Lett. 93 (2004) 065502-1. L.O. Paz-Barbon, R.L. Johnston, et al. J. Chem. Phys. 128 (2008) 134517. R. Ismail, R.L. Johnston, Phys. Chem. Chem. Phys. 12 (2010) 8607. F. Pittaway, L.O. Paz-Borbón, R.L. Johnston, et al. J. Phys. Chem. C 113 (2009) 9141. R. Zanella, S. Giorgio, C.R. Henry, C. Louis, J. Phys. Chem. B 106 (2002) 7634. M. Mihaylov, H. Knozinger, et al. Chem. Ing. Tech. 79 (2007) 795. F. Boccuzzi, A. Chiorino, M. Mazzoli, Surf. Sci. 454-456 (2000) 942. R. Meyer, C. Lemire, S. K. Shaikhutdinov, H. J. Freund, Gold. Bull. 37 (2004) 72. Tessier, A. Rakai, F. Bozon-Verduraz, J. Chem. Soc. Faraday Trans 88 (1992) 741. X. P. Xu, D. W. Goodman, J. Phys. Chem. 97 (1993) 7711. V. Yudanov, R. Sahnoun, et al. J. Phys. Chem. B 107 (2003) 255. H. L. Abbott, A. Aumer, Y. Lei, et al., J. Phys. Chem. C 114 (2010) 17099. K. Luo, T. Wei, C. W. Yi, et al. J. Phys. Chem. B 109 (2005) 23517. T. Wei, J. Wang, D. W. Goodman, J. Phys. Chem. C 111 (2007) 8781. 
[46] F. Cardenas-Lizana, S. Gomez-Quero, et al.J. Catal. 262(2), 235-243, 2009

[47] F. Gao, Y. L. Wang, D. W. Goodman, J. Phys. Chem. C 113 (2009) 14993.

[48] S. M. Oxford, P. L. Lee, P. J. Chupas, et al. J. Phys. Chem. C 114 (2010) 17085.

[49] S. A. Tenney, J. S. Ratliff, C. C. Roberts, et al. J. Phys. Chem. C 114 (2010) 21652.

[50] S. A. Tenney, W. He, C. C. Roberts, et al. J. Phys. Chem. C 115 (2011) 11112.

[51] J. Kiss, L. Ovari, A. Oszko, G. Potari, et al. Catal. Today 181 (2012) 163.

[52] W.R. Tyson, W.A. Miller, Surf. Sci. 62 (1) (1977) 267.

[53] L.Z. Mezey, J. Giber, Jpn. J. Appl. Phys. 21 (1982) 1569.

[54] Hussain, A.J. Muller, et al., Top Catal. 54 (2011) 415.

[55] M. Gajdos, A. Eichler, and J. Hafner, J. Phys. : Condens. Matter. 16 (2004) 1141.

[56] Hammer, J. K. Nørskov, Advances in Catalysis 45 (2000) 71.

[57] M. García-Mota, N. Lopez, Phys. Rev. B 82 (2010) 075411.

[58] T. Mineva, N. Russo, H. Freund, J. Phys. Chem. A 105 (2001) 10723.

[59] G.J. Blyholder, J. Phys. Chem. 68 (1964) 2772.

[60] H.J. Gotsis, I. Rivalta, E. Sicilia, N. Russo, Chem. Phys. Lett. 468 (2009) 162.

[61] L. Guczi, A. Beck, et al., J. Mol. Catal. A: Chem. 204-205 (2003) 545.

[62] A.M. Venezia, L.F. Liotta, et al. Appl. Catal. A 251 (2003) 359.

[63] Z. Suo, C. Ma, M. Jin, T. He, L. An, Catal. Commun. 9 (2008) 2187.

[64] A. M. Molenbroek, S. Helveg, H. Topsøe, B. S. Clausen, Top Catal 52 (2009) 1303. 